\title{
The importance of economic, social and cultural capital in understanding health inequalities: using a Bourdieu- based approach in research on physical and mental health perceptions
}

\section{Wouter Pinxten and John Lievens}

\author{
Department of Sociology, Ghent University
}

Abstract In this article we adopt a Bourdieu-based approach to study social inequalities in perceptions of mental and physical health. Most research takes into account the impact of economic or social capital on health inequalities. Bourdieu, however, distinguishes between three forms of capital that can determine peoples' social position: economic, social and cultural capital. Health research examining the effects of cultural capital is scarce. By simultaneously considering and modelling indicators of each of Bourdieu's forms of capital, we further the understanding of the dynamics of health inequalities. Using data from a large-scale representative survey $(N=1825)$ in Flanders, Belgium, we find that each of the forms of capital has a net effect on perceptions of physical and mental health, which persists after controlling for the other forms of capital and for the effects of other correlates of perceived health. The only exception is that the cultural capital indicators are not related to mental health. These results confirm the value of a Bourdieu-based approach and indicate the need to consider economic, social and cultural capital to obtain a better understanding of social inequality in health.

Keywords: Bourdieu, economic, social and cultural capital, cultural participation, physical and mental health, SF-12

\section{Introduction}

Social position remains an important determinant of health: 'differential health status is probably the most enduring and incontrovertible indication of class' (Bennett et al. 2009: 152). More research, however, is necessary to fully understand the dynamics of the social divide in health (Mackenbach 2012).

In this article we examine the usefulness of Bourdieu's theory of capital in studying differences in physical and mental health. Bourdieu (1984) argues that people from different social positions differ from one another with regard to their possession of three forms of capital: social, cultural and economic capital. Each of these forms of capital can be considered as a resource that might be useful for acquiring or maintaining good health: 
The resources needed to select or adopt specific health-relevant lifestyles emerge from the interplay between economic, social and cultural capital. In this dynamic form social inequalities affect - through collective behavioural variations - people's health status and risks.

(Abel 2008: 3)

Recent health research has paid much attention to economic and social capital but cultural capital lags behind in relevant studies.

By adopting a Bourdieusian approach and consequently considering the three forms of capital, this article furthers discussions on social determinants of health in two ways. Firstly, by simultaneously including indicators of the three forms of capital we can assess the net effects of each of them. Secondly, we pay particular attention to the cultural capital component, which remains largely unexplored in health research to date, and include measurements for institutionalised (education) and embodied (cultural participation) cultural capital.

\section{The social gradient in health}

The social gradient in health refers to the gradual positive association between social position and health that is observed for a wide variety of health indicators (Adler et al. 1994). This gradient implies that each improvement or worsening of someone's social position is associated with a similar change in health. Although the direction of causality could be questioned, research shows that it is social position that impacts on health (Carpiano et al. 2008).

Despite all research on the social gradient, questions remain about its existence and persistence (Mackenbach 2012). Moreover, a great deal of discussion remains concerning the definition and operationalisation of social position. Carpiano et al. (2008) attribute this to the complex nature of social position: "Social class remains largely a "black box" of causal factors and mechanisms' (p. 246). Even with regard to the terminology there is no consensus: the terms social class, social status, social inequality, social stratification and socioeconomic position are used seemingly at random without any reference to the theoretical background (Liberatos et al. 1998). As Krieger et al. (1997: 342) posit:

When socioeconomic data are included in public health analyses, they often are presented with little or no theoretical justification, are measured and modelled eclectically, and are primarily used by researchers to 'control' for, rather than study the effects of, socioeconomic position on health.

Prandy (1999) also refers to the multidimensional nature of social position which should be taken into account in its measurement.

In summary, we can say that a great deal of work has been done with regard to examining the social gradient in health. However, questions remain and appropriate measurements of social position should be taken into account. In this regard, a Bourdieusian approach toward social position seems promising (Abel 2007 2008, Veenstra 2007). We will discuss its merits in detail in the following section.

\section{A Bourdieu-based framework in health research}

Central to Bourdieu's (1984) theoretical framework is the concept of habitus, which refers to a system of dispositions that guides people's choices and attitudes. The habitus expresses itself 
in all domains of life: in aesthetic preferences, cultural practices and choices related to health behaviour; in short, in lifestyles and in ways of being.

While Bourdieu's conception of habitus changes throughout his oeuvre (Daenekindt and Roose 2012) the constant theme is that individuals are disposed because they are exposed (Bourdieu 2000). Individuals are socialised by their environment and people living in similar life conditions - that is, occupying a similar position in social space - tend to develop a similar habitus, thus sharing similar lifestyles. Accordingly, there is a homology between the social space and the space of lifestyles. People's tastes, preferences and behaviour are consequently structured along the configuration of social space, and lifestyles can be considered a marker of social position (Bourdieu 1984).

To situate people in social space, Bourdieu introduced his theory of capital. Bourdieu (1986) criticises the focus on monetary exchange and defines capital as 'accumulated labor (in its materialised form or its "incorporated" embodied form)' (p. 241). In particular, Bourdieu considers the amount and composition, and the evolution in the amount and composition of three forms of capital to determine an individual's position in social space, that is, social, economic and cultural capital. He furthermore stresses the interplay between the different forms of capital in that they can be converted into one another and that the use and the acquisition of a specific capital form depends on the other forms of capital.

Bourdieu's concept of social position is relational, in that people's social position depends on their relationship to the position of others in social space. People with a similar amount and composition of the different forms of capital are closer together in social space, and this group of people consequently has the potential to become a social class. Possession of these forms of capital, furthermore, determines people's power position in specific fields. A field refers to a specific social arena in social life (Bourdieu 1984). In each field, specific power dynamics are at play, which makes certain people more adapted than other to act in this field.

Bourdieu never conducted research on health, but his capital theory can be applied to the study of health inequalities. Each of the forms of capital and the interplay between them, can in this respect be considered as important in acquiring or maintaining good health (Abel and Frohlich 2012). The application of this framework has several merits. Firstly, it provides a theoretical background for interpreting differences in health, instead of merely establishing them (Abel 2007). Secondly, it allows us to account for the claim that a diverse gamut of resources is important in understanding health inequalities (Grineski 2009). Thirdly, Bourdieu's framework offers an insight into frequently neglected indicators of social structure that influence health, such as cultural elements (Veenstra 2007). Finally, Morrow (1999) stresses that this framework is especially useful for avoiding ending up in the deficit theory syndrome, which refers to approaches emphasising the resources that unsuccessful individuals lack. Bourdieu's theory stresses the resources that people have and not the resources they lack, which makes it more a theory of privilege than a theory of inadequacy.

In the following sections, we summarise the literature on the possible health effects of each form of capital. Our discussion of economic and social capital is limited, since a large amount of literature already exists on this subject. Instead, we pay particular attention to studies that examine the impact of cultural capital on health, an association that has received only scant attention thus far (Abel 2008).

\section{Economic capital}

Economic capital refers to material assets that are 'immediately and directly convertible into money and may be institutionalized in the form of property rights' (Bourdieu 1986: 242). Economic capital includes all kinds of material resources (for example, financial resources, land or property ownership) that could be used to acquire or maintain better health. 
We distinguish between two pathways to explain the impact of economic capital on health (Mirowksy and Ross 2003). In the materialist interpretation, the amount of material resources is positively related to health outcomes. Following this interpretation, actual differences in material resources determine the probability that an individual encounters health problems or stress and which health behaviours they adopt. The psychosocial interpretation emphasises the social meaning of differences in the available amount of economic capital. In this respect, having little economic capital can cause more stress and feelings of powerlessness, thus adversely influencing health.

\section{Social capital}

Social capital has received a substantial amount of attention in past decades. Song (2013) distinguishes between two schools of thought on social capital. Advocates of the first school (such as Coleman and Putnam), consider social capital as a collective feature of society (for example, a general level of trust), which cannot be possessed by individuals. In Bourdieu's account, by contrast, social capital is a network-based resource that is available in relationships and consequently accrues to individuals. He defines social capital as 'the aggregate of the actual or potential resources which are linked to the possession of a durable network of more or less institutionalized relationships of mutual acquaintance and recognition' (Bourdieu 1986: 247). Social capital is used both as a network-based and a collective feature in health research, but few studies refer to Bourdieu (Song 2013).

What is problematic in Bourdieu's social capital theory is that he never described how it should be measured. Ziersch (2005), Carpiano (2006) and Song (2011) have all paid attention to operationalising network-based approaches of social capital. Ziersch (2005) distinguishes between two mutually influencing components of social capital. The social capital infrastructure consists of both cognitive (for example, trust) and structural (for example, formal and informal networks) elements. The social capital resources in turn seem to result from the infrastructure, like social support and social cohesion. Carpiano (2006) applied Bourdieu's framework to create a neighbourhood resource-based theory of social capital. He distinguishes between structural antecedents (for example, the ethnic or social composition of a neighbourhood), social cohesion and social capital. Carpiano differentiates between four types of social capital that can be available in social networks: social support, social leverage, informal social control and community organisation participation. In contrast to Ziersch and Carpiano, Song (2011) reserves the term social capital exclusively for the resources that are available in a social network. She argues that although social capital, social cohesion, social integration and social support are often used interchangeably, social capital should be considered a distinct concept.

Song (2011) summarises 10 mechanisms through which social capital can have a direct impact on health. These mechanisms vary from reduced stress and isolation and applying healthier norms and behaviour to more access to information and health facilities.

\section{Cultural capital}

Although only limited attention has been paid to cultural capital in health research thus far (Abel 2008), it might be relevant as well:

If it is true that cultural capital has comparable qualities to other forms of capital, then it may also be true that accumulation of such capital leads to improved health outcomes.

(Khawaja and Mowafi 2006: 445)

Mackenbach (2012), moreover, identifies cultural capital as a promising approach to explain health inequalities. 
Bourdieu (1986) distinguishes between three forms of cultural capital. Cultural capital in the institutionalised state refers to educational attainment. Objectified cultural capital concerns the possession of cultural goods. The embodied or incorporated state refers to people's values, skills, knowledge and tastes. Education - (that is, institutionalised cultural capital) - is often used as a health determinant in research (Muntaner et al. 2003), but there are indications that embodied cultural capital is also relevant to health: 'it is in this form that cultural capital becomes a key component that links people's social position with the behavioural aspects of health inequality' (Abel 2008: 2). We consequently focus on the effects of this type of cultural capital on health. Furthermore, we stay close to Bourdieu's account of embodied cultural capital by assessing differences in cultural participation (Yaish and Katz-Gerro 2010). Another approach towards embodied cultural capital focuses on health-related knowledge, skills and beliefs (or health lifestyles), for example, the knowledge of medical terms or communication skills (Cockerham 2005, Shim 2010). These authors consider embodied cultural capital in a field-specific way.

In recent years, studies have indicated that embodied cultural capital defined as cultural participation matters to health. Wilkinson et al. (2007) showed that the amount of cultural activities in which respondents participate is positively related to self-rated health, after controlling for socio-demographic variables. Bygren et al. (2009a), Johansson et al. (2001) and Nummela et al. (2008) also observed a positive net effect of cultural participation on self-rated health. Other studies established positive net effects of different indicators of cultural participation on survival and mortality (Bygren et al. 2009b, Glass et al. 1999, Konlaan et al. 2000, Hyyppä et al. 2005, Väänänen et al. 2009). Grossi et al. (2011) associated cultural participation with better mental health.

The studies cited above examined the impact of cultural participation on health. This might have an important drawback since it is unclear whether the beneficial health effects result from participation in cultural activities as such, or instead from participating in outdoor activities (Bygren et al. 2009b). More elaborate accounts of cultural capital have been used in other studies. Cuypers et al. (2012), for example, demonstrated that both receptive cultural participation (attending a concert) and active cultural participation (such as sculpting or painting) are related to fear, depression, life satisfaction and general health, after controlling for socio-demographic variables. Frie and Janssen (2009) plotted indicators of social position, lifestyle and health in a three-dimensional space and observed that lifestyles are related to physical functioning and self-rated health. Pampel (2012) found that both cultural participation and tastes are important in understanding differences in body weight, after controlling for socioeconomic status.

We wish to go further than the studies cited above in three ways. Firstly, we also take measurements of social and economic capital into account (similar to Grineski 2009, Veenstra 2007, Veenstra and Patterson 2012). Secondly, we include measurements for several aspects of cultural capital. Finally, we take recreational participation into account, to examine whether this affects health.

The important question that remains is why cultural participation could positively affect health. Bygren et al. (2009a) discussed three alternative explanatory schemes. The philosophical discourse focuses on the positive effect of aesthetic experiences, which help individuals to contextualise and accept their situation. The biological and psychological approach refers to its effects on brain structure and cognitive functioning. Psychological explanations focus on improved capacities to express and interpret emotions. Yet another possible explanation is more closely related to Bourdieu's work: cultural capital can be considered as an important bearer of meaning and an essential element of social hierarchy in contemporary society (Elchardus 2009, Katz-Gerro 2004, Veenstra 2007). Cultural capital thus marks differences in 
social standing, lifestyles, openness to experiences and symbolic resources that can be used to improve health.

\section{Research questions}

Our central research question is to what extent the three forms of capital (economic, social and cultural) explain differences in health, after controlling for one another and for other health determinants. Since these forms of capital supplement each other (Bourdieu 1986), we follow the recommendation to consider simultaneously the three forms of capital (Grineski 2009, Stephens 2008, Veenstra 2007). We expect that higher levels of capital, in its three forms, are positively associated with health.

\section{Methods}

\section{Data}

This study draws on data from 'Sexual Health in Flanders' (Buysse et al. 2013), a large-scale representative survey on sexual health in Flanders (Belgium). Respondents aged between 14 and 80 were randomly selected from the Belgian National Register. All data were gathered via face-to-face interviews, with a combination of computer-assisted personal interviewing and computer-assisted self-interviewing. Data were collected between February 2011 and January 2012 and the final database consists of 1832 respondents (a response rate of 40 per cent of the eligible respondents). After data collection, the data were weighted by gender, age and schooling level to make it representative of the Flemish population aged 14 to 80 .

\section{Data analysis}

We used ANOVA with Welch F-tests to estimate the bivariate association between the independent variables and the health measurements. In the multivariate analyses, we applied ordinary least squares regression. We used $\mathrm{R}^{2}$-change $\mathrm{F}$-tests to determine whether categorical variables as a whole, contributed statistically significantly to explaining the variation in the dependent variable. All analyses were carried out on the weighted dataset.

\section{Operationalisation}

We drew on the short-form health survey (SF-12) to measure health (Ware et al. 1996). This provides a valid assessment of physical and mental health in a general population (Gandek et al. 1998). The SF-12 includes questions on diverse aspects of people's functioning and comprises two subscales. The physical component subscale measures the respondents' perception of their physical health. By summing the scores for the different items we obtained a sum score ranging from 6 to 20 with a mean of $16.83(S D=2.8)$. The mental component subscale measures the respondents' perception of their mental health. The sum score for this scale ranged from 9 to 27 with a mean of $22.02(S D=3.3)$. The higher the score, the better the respondents' evaluation of their health.

To measure economic capital, we used a question on the respondents' perception that they could live comfortably within their available income. Answers ranged on a seven-point scale from 'it is very difficult to live comfortably' to 'we can live very comfortably'. This question captures the extent to which respondents had sufficient resources to meet their daily needs and is an indicator of economic capital. We recoded this indicator into a variable with three categories, distinguishing between people who have difficulty living comfortably (answers 1-3), 
people who do not find it really difficult to live comfortably (answers 4-5) and people who find it very easy to live comfortably (answers 6-7). In the questionnaire, respondents were also asked to indicate their actual family income. However, we decided not to use this variable in this article because 15 per cent of the respondents refused to answer, whereas non-response was close to zero for the question on subjective income. Additional analyses, moreover, revealed a strong association between the subjective and the actual income variable. People experiencing difficulty in living comfortably have a mean monthly income of $€ 1804$ (median $=€ 1650$ ), people who have no real difficulty in living comfortably have a mean income of $€ 2453$ (median $=€ 2450$ ) and the group that finds it easy to live comfortably has a mean income of $€ 3094$ (median $=€ 3224$ ). Differences between these mean incomes are statistically significant at the 0.001 level, which also applies to all pairwise comparisons (ANOVA Welch F-test with Games-Howell post hoc tests).

In line with Bourdieu, we focused on social capital as a network-based resource. An important limitation, however, is that no measurements of the resources of the respondents' network members were included in the questionnaire. To account somewhat for differences in social capital we included two other network-based measurements: neighbourhood social cohesion and social support. We are aware that these are distinct theoretical concepts that cannot be equated with a strict conceptualisation of social capital. However, both Ziersch (2005) and Carpiano (2006) included social support and social cohesion as part of their conceptual model of social capital, which provides some justification of the inclusion of these indicators.

To measure social cohesion in the respondent's neighbourhood, we used a subscale of Sampson, Raudenbush and Earl's (1997) collective efficacy measure. Respondents had to indicate to what extent they agreed with each of five statements regarding their neighbourhood. Answers ranged on a five-point scale from 'strongly disagree' to 'strongly agree'. A Cronbach's alpha of 0.822 indicates strong internal consistency for the different items. We took the sum score and divided it into three categories: low (sum score of 17 or less), moderate (sum score from 18 to 20) and high (sum score larger than 20) neighbourhood cohesion.

We operationalised social support with five items measuring the extent to which a respondent could rely on others in five situations: for talking to someone, for going on a day out, if they are ill, if they have financial problems, or for emotional support when someone dies. Answers ranged on a five-point scale from 'strongly disagree' to 'strongly agree'. Scores on the five items were summed (Cronbach's alpha $=0.73$ ) and recoded into three categories: little social support (sum score of 18 or less), a moderate amount of social support (sum score from 19 to 22) and a high level of social support (sum score higher than 22).

We include measurements for both institutionalised and embodied cultural capital. To measure institutionalised cultural capital we used the respondent's educational level. With regard to embodied cultural capital, we included two measurements for outdoor participation. The first focused explicitly on participation in cultural activities (Yaish and Katz-Gerro 2010). The second captured the amount of other recreational activities that respondents participated in. We included the latter to test whether there were differences between the effects of attending cultural or recreational activities. In this way we took into account the suggestion of Bygren et al. (2009b) that 'it would be useful to know whether there are health benefits to be gained from attending cultural events that may have broader appeal or from other leisure time stimulation' (p. 70).

We distinguished between five categories in our measurement for educational level: still going to school; no education completed or primary school education completed; lower secondary education completed; higher secondary education completed; higher education completed.

Cultural participation was assessed by four different cultural activities: attending a concert; attending a musical, show, revue or stand-up comedy; attending a play, ballet or dance performance; visiting a museum or exhibition. Respondents could answer on a seven-point scale, 
ranging from 'not in the past 6 months' to 'daily'. We recoded the four questions into one item with three categories. The first category comprises the non-participants; the second includes the respondents who participate occasionally (one to three activities); the last category consists of those who participate frequently (more than three activities).

We included two items capturing other recreational activities: going to a zoo or an amusement park and going to a fair. Respondents could answer on a seven-point scale how often they had participated in each of these activities in the previous 6 months. We distinguished between respondents who did not visit a zoo, fair or amusement park in the previous 6 months; those who occasionally visited them (one or two activities); and respondents who visited them frequently (three or more activities).

In the previous paragraphs, we presume that it is cultural participation that influences health. However, people with poorer health may experience health-related barriers to participation, which could also explain an association between not participating and worse health. To control for this possibility, we included a variable on active sports participation: we distinguished between people who engaged in sports at least once a week and people who did so less than once a week. Finally, we controlled for age and gender.

\section{Results}

Table 1 summarises the descriptives of the sample. ANOVAs show that there are statistically significant differences in the mean physical and mental health perception scores between the categories for all the independent variables. However, there are two exceptions: the mean mental component scores of the respondents in the different age groups and of the recreational participation groups do not differ statistically significantly from one another.

The results of the multivariate analyses are shown in Table 2. Moreover, we conducted $\mathrm{R}^{2}$ change F-tests to determine whether the categorical variables as a whole contribute statistically significantly to the model (not shown). To obtain this parameter, we performed stepwise regressions of the final model, where we exclude one of the variables with multiple dummies in the second step of a stepwise regression. The resulting $\mathrm{R}^{2}$-change parameter indicates whether the proportion of explained variance changes statistically significantly. This operation was repeated for all the measurements with multiple dummy variables.

For physical health, we observed statistically significant effects of gender, age and sports participation. Women and elderly respondents had lower scores compared with the reference group, whereas people aged 26 to 40 and people engaging in sports frequently perceived they had better physical health.

Economic capital has an effect in the expected direction: a lower degree of economic capital is associated with perceptions of having worse physical health. Furthermore, we observed that a low level of social support is negatively related to physical health. In respect of cultural capital, we observed that non-participants show worse health than people who participate occasionally.

For mental health, gender, age and participating in sports have an effect. Women and young people score lower on mental health perceptions than their respective reference group. However, the $\mathrm{R}^{2}$-change statistic indicates that age does not make a statistically significant contribution to the model. Respondents participating in sports had higher mean scores for mental health compared with those not doing so.

For economic capital we observed that people without financial problems perceived they had better mental health than the reference group. In addition, we found a negative effect of a low level of social support and a positive effect of high neighbourhood social cohesion on perceptions of mental health. Finally, people with lower secondary education had higher 
Importance of capital in understanding health inequalities 9

Table 1 Descriptives of the sample with mean physical (PCS) and mental component scores (MCS) and ANOVA Welch F-tests

\begin{tabular}{|c|c|c|c|c|c|c|}
\hline & & Percentage & $\begin{array}{l}\text { Mean } \\
\text { PCS }\end{array}$ & $A N O V A$ & $\begin{array}{l}\text { Mean } \\
\text { MCS }\end{array}$ & $A N O V A$ \\
\hline \multirow[t]{2}{*}{ Gender } & Male & 49.8 & 17.2 & $(1,1759)=27.3^{* *}$ & 22.7 & $(1,1730)=88.5^{* *}$ \\
\hline & Female & 50.2 & 16.5 & & 21.3 & \\
\hline \multirow[t]{5}{*}{ Age } & $14-25$ & 19.1 & 17.6 & $(4,835)=33.6^{* *}$ & 21.7 & $(4,853)=1.4$ \\
\hline & $26-40$ & 23.5 & 17.5 & & 22.2 & \\
\hline & $41-54$ & 25.1 & 16.9 & & 22.1 & \\
\hline & $55-65$ & 17.1 & 16.3 & & 22.2 & \\
\hline & $65+$ & 15.2 & 15.3 & & 21.9 & \\
\hline \multirow[t]{2}{*}{ Sports } & $\begin{array}{l}\text { Not/seldom } \\
\text { participating } \\
\text { in sports }\end{array}$ & 49.5 & 16.2 & $(1,1670)=90.5^{* *}$ & 21.5 & $(1,1759)=40.2^{* *}$ \\
\hline & $\begin{array}{l}\text { Frequently } \\
\text { participating } \\
\text { in sports }\end{array}$ & 50.5 & 17.4 & & 22.5 & \\
\hline \multirow[t]{3}{*}{ Income } & $\begin{array}{l}\text { Difficult to live } \\
\text { comfortably }\end{array}$ & 12.5 & 15.6 & $(2,594)=26.7^{* *}$ & 21 & $(2,583)=23.1^{* *}$ \\
\hline & $\begin{array}{l}\text { Not really } \\
\text { difficult to live } \\
\text { comfortably }\end{array}$ & 39.9 & 16.7 & & 21.7 & \\
\hline & $\begin{array}{l}\text { Easy to live } \\
\text { comfortably }\end{array}$ & 46.5 & 17.3 & & 22.5 & \\
\hline \multirow[t]{3}{*}{ Social support } & Little & 19.4 & 16.1 & $(2,840)=11.6^{* *}$ & 21.3 & $(2,853)=12.1^{* *}$ \\
\hline & Moderate & 50.4 & 16.9 & & 22.1 & \\
\hline & Much & 30.2 & 17.1 & & 22.4 & \\
\hline \multirow{3}{*}{$\begin{array}{l}\text { Neighbourhood } \\
\text { social cohesion }\end{array}$} & Little & 32.2 & 16.7 & $(2,1164)=4.1^{*}$ & 21.5 & $(2,1168)=15.3^{* *}$ \\
\hline & Moderate & 33.4 & 17.1 & & 22 & \\
\hline & Much & 31.4 & 16.6 & & 22.6 & \\
\hline \multirow[t]{5}{*}{ Education } & Going to school & 11.6 & 17.7 & $(4,828)=27^{* *}$ & 22.1 & $(4,806)=2.6^{*}$ \\
\hline & $\begin{array}{l}\text { No education/ } \\
\text { only primary } \\
\text { school education }\end{array}$ & 18.2 & 15.7 & & 21.7 & \\
\hline & $\begin{array}{l}\text { Lower secondary } \\
\text { education }\end{array}$ & 20.5 & 16.6 & & 22.1 & \\
\hline & $\begin{array}{l}\text { Higher secondary } \\
\text { education }\end{array}$ & 22.6 & 16.8 & & 21.8 & \\
\hline & Higher education & 27.1 & 17.4 & & 22.4 & \\
\hline \multirow{3}{*}{$\begin{array}{l}\text { Cultural } \\
\text { participation }\end{array}$} & No participation & 39.3 & 16.3 & $(2,906)=21.6^{* *}$ & 21.7 & $(2,931)=4.3^{*}$ \\
\hline & $\begin{array}{l}\text { Occasional } \\
\text { participation }\end{array}$ & 42.4 & 17.3 & & 22.2 & \\
\hline & $\begin{array}{l}\text { Frequent } \\
\text { participation }\end{array}$ & 18.3 & 17 & & 22.2 & \\
\hline \multirow{3}{*}{$\begin{array}{l}\text { Recreational } \\
\text { participation }\end{array}$} & No participation & 46.4 & 16.5 & $(2,1112)=13.1^{* *}$ & 21.9 & $(2,1066)=0.782$ \\
\hline & $\begin{array}{l}\text { Occasional } \\
\text { participation }\end{array}$ & 27.1 & 17.1 & & 22.1 & \\
\hline & $\begin{array}{l}\text { Frequent } \\
\text { participation }\end{array}$ & 26.5 & 17.1 & & 22.2 & \\
\hline
\end{tabular}

${ }^{*} P<0.05 ; * * P<0.001$. The physical component scores range between 6 and 20 ; the mental component scores between 9 and 27. 
Table 2 Unstandardised effects of economic, social and cultural capital on the physical (PCS) and mental (MCS) component scale from the SF-12, controlled for gender, age and sports participation

\begin{tabular}{|c|c|c|c|}
\hline & & $P C S$ & $M C S$ \\
\hline Intercept & & $17.29^{* * * *}$ & $21.97^{* * *}$ \\
\hline \multirow[t]{2}{*}{ Gender } & Male (ref.) & - & - \\
\hline & Female & $-0.57^{* * * *}$ & $-1.32^{* * * *}$ \\
\hline \multirow[t]{5}{*}{ Age } & $14-25$ & 0.36 & $-0.79^{* *}$ \\
\hline & $26-40$ & $0.39 *$ & -0.07 \\
\hline & $41-54$ (ref.) & - & - \\
\hline & $55-65$ & -0.34 & 0.15 \\
\hline & $65+$ & $-1.13^{* * *}$ & 0.01 \\
\hline \multirow[t]{2}{*}{ Sports } & Not/seldom participating in sports (ref.) & - & - \\
\hline & Frequently participating in sports & $0.61^{* * * *}$ & $0.69^{* * * *}$ \\
\hline \multirow[t]{3}{*}{ Income } & Difficult to live comfortably & $-0.76^{* * *}$ & -0.38 \\
\hline & Not really difficult to live comfortably (ref.) & - & - \\
\hline & Easy to live comfortably & 0.24 & $0.68^{* * *}$ \\
\hline \multirow[t]{3}{*}{ Social support } & Little & $-0.56^{* *}$ & $-0.82^{* * *}$ \\
\hline & Moderate (ref.) & - & - \\
\hline & Much & 0.15 & 0.29 \\
\hline \multirow[t]{3}{*}{ Neighbourhood social cohesion } & Little & -0.02 & -0.11 \\
\hline & Moderate (ref.) & - & - \\
\hline & Much & -0.13 & $0.53^{* *}$ \\
\hline \multirow[t]{5}{*}{ Education } & Going to school & 0.16 & 0.66 \\
\hline & No education/only lower education & -0.36 & 0.34 \\
\hline & Lower secondary education & 0.14 & $0.53 *$ \\
\hline & Higher secondary education (ref.) & - & - \\
\hline & Higher education & 0.28 & 0.39 \\
\hline \multirow[t]{3}{*}{ Cultural participation } & No participation & $-0.44^{* *}$ & -0.31 \\
\hline & Occasional participation (ref.) & - & - \\
\hline & Frequent participation & -0.23 & -0.18 \\
\hline \multirow[t]{3}{*}{ Recreational participation } & No participation & -0.26 & -0.1 \\
\hline & Occasional participation (ref.) & - & - \\
\hline & Frequent participation & -0.21 & 0.098 \\
\hline$N$ & & 1729 & 1727 \\
\hline Adjusted $\mathrm{R}^{2}$ & & 14.4 & 10.1 \\
\hline
\end{tabular}

$P<0.05 ; * * P<0.01 ; * * * P<0.001$. Ref., reference.

mental health scores than people with higher secondary education. However, the $\mathrm{R}^{2}$-change Ftest indicates that educational level does not make a statistically significant contribution to the model.

Thus far we only included measurements of the amount of capital in the analyses. Bourdieu (1986), however, emphasises the interplay between the different forms of capital. To model this interplay, we tested for interactions between the different forms of capital (not shown). In line with Bourdieu's work (1986) we would expect some sort of compensation and accumulation. However, only in three pairwise interactions were some of the interaction terms statistically significant and these interaction effects were not consistently interpretable. Due to this lack of clear patterns in the interaction effects we consider the model without interaction terms to be more parsimonious. 


\section{Discussion}

In this article, we adopt Bourdieu's capital theory to examine the impact of the different forms of forms of capital on perceptions of mental and physical health. It is important to acknowledge in this regard that each of the forms of capital can be used as a resource to acquire or maintain good health (Abel and Frohlich 2012).

This article contributes to the discussion on social determinants of health in three ways. Firstly, we confirm the importance of simultaneously including measurements of the different forms of capital since they complement each other, as has already been indicated in previous research (Veenstra 2007, Veenstra and Patterson 2012). In this regard, the results indicate that indicators of each of the forms of capital have positive net effects on physical and mental health, with the exception of cultural capital in the analysis of mental health perceptions. The effects of the forms of capital remain after controlling for one another and for gender, age and participation in sports. Secondly, the results point out that cultural participation, as an indicator of embodied cultural capital, is relevant to study health differences: however, it applies only to physical health. Finally, the differences in the results for cultural and recreational participation suggest that the beneficial effect on physical health is related to the specific context of participation in cultural activities and not to participation in outdoor activities as such.

We observe that a low level of economic capital has a negative effect on perceptions of physical health and that people with more economic capital perceive their mental health as being better than the reference group. These results suggest there is a positive association between economic capital and measures of health. This positive association is probably related to the increased availability of both better material and psychosocial resources to people with more economic capital (Mirowsky and Ross 2003).

Furthermore, social support correlated positively with both mental and physical health. Neighbourhood social cohesion is related only to perceptions of mental health. Song (2011) summarises ways in which social capital can enhance health. In our opinion, these can also be applied to social support and neighbourhood social cohesion. The beneficial effect of social support and cohesion can thus be attributed to various mechanisms from reduced stress and isolation and applying healthier norms and behaviour to better access to information and health facilities.

The results for the different cultural capital items differ. Education is unrelated to both physical and mental health, which seems somewhat surprising, since most studies find education to be positively associated with health (Kamin et al. 2013). The latter authors argue, however, that the impact of education on health might decrease due to increasing numbers of people with a higher educational degree. This increase partly reduces the value of education: "education alone does no longer guarantee improved life chances' (p. 109). Furthermore, cultural participation has a net positive effect on physical but not on mental health perception. To test whether the effect of cultural participation is due to the specific context of cultural participation or to spending leisure time outdoors, we included a measurement for recreational participation. This indicator, however, is unrelated to health, either physical or mental. We found that an effect of cultural but not of recreational participation on physical health suggests that the positive effect of cultural participation is related to its specific context. There are different explanations for the association between health and cultural participation: cultural participation can make people more at ease with their life, it can influence cognitive functioning or the brain structure or it can increase the capacity to express and interpret emotions (Bygren et al. 2009a). Another explanation is more closely related to Bourdieu's own work: it is also possible that cultural capital acts as a bearer of symbolic meaning, thus embodying an essential element of social hierarchy (Abel 2008, Khawaja and Mowafi 2006, Pampel 2012, Veenstra 
2007). Accordingly, cultural capital is associated with social standing, lifestyles, openness to experiences and symbolic resources that might impact on health. Furthermore, that cultural participation is only associated with physical health might help eliminate some possible explanations. If the beneficial effect is related to a better capacity to express and interpret emotions, we would expect a stronger effect on mental health perceptions and less on physical health. The same applies to the explanation that cultural participation makes people more at ease with their life. The absence of an effect on mental health consequently might suggest that the effect on physical health is explained by differences in cognitive functioning or brain structure or differences in social standing, lifestyles and available symbolic resources. This, however, remains a tentative interpretation.

Finally, we tested pairwise interactions between the capital variables to incorporate the interplay between the forms of capital. However, only three of these interactions were statistically significant and they were not easily interpretable. This is in line with Veenstra and Patterson's (2012) study on the impact of the different forms of capital on mortality. They found only a few marginally significant interaction terms. These results might suggest that the interplay between the different forms of capital is less important in explaining health differences. This, however, seems surprising given the importance that Bourdieu paid to this interplay. Alternatively it might be due to a limited operationalisation of our measures and the limited modelling of the capital interplay.

There are some important limitations to this study. Firstly, by focusing on differences in the amount of capital we miss an interesting feature of Bourdieu's (1984) theory of capital, that is, that of social position as a relational construct. As put forward by Muntaner et al. (2003), the relational aspect and social stratification are two distinct facets of social inequality. Our focus on the amount of capital allows us to account for differences in social stratification but we cannot measure the relational aspect. Bourdieu applied multiple correspondence analysis to model this feature of social position. With this technique, however, it is not possible to calculate net effects or significance tests.

Secondly, we used interaction terms to model the interplay between the forms of capital. However, this interplay is much more complex (Abel and Frohlich 2012, Bourdieu 1986). For example, we cannot assess how people convert one form of capital into another. Longitudinal studies offer interesting possibilities in this regard. Thirdly, we are aware that we cannot claim causality based on this cross-sectional dataset. For instance, we control for sports participation to limit the possibility of reverse causality in the association between cultural participation and health. However, despite the inclusion of this indicator it is still possible that long-standing illness or impairment explains the association of cultural participation and physical health. We have no adequate measures to take this into account, which is an important limitation.

Finally, the operationalisation of the different forms of capital is crude. With regard to social capital, we used measures of social support and social cohesion. Although these concepts are integrated in both Ziersch (2005) and Carpiano's (2006) conceptualisation of social capital, we are aware that this is very limited since these are only two elements from Ziersch and Carpiano's conceptualisation, whereas others are not included. More importantly this ignores Song's (2011) critique that social support, social cohesion and social capital are incorrectly used interchangeably. Song asserts that social capital refers exclusively to the resources of one's network members and that it should be studied as such. We did not capture this dimension, which is a significant limitation of our study. Relating to cultural capital, we did not include measurements of attitudes, preferences and tastes, which is a distinct set of cultural capital indicators (Yaish and Katz-Gerro 2010). Furthermore, we did not measure health-related cultural capital, that is, healthy lifestyles (Cockerham 2005, Shim 2010). From this point of view, various kinds of health behaviour, knowledge, beliefs and skills (for example, smoking, drinking, 
knowledge of medical terms and communication skills) are important in explaining health inequalities.

Finally, we formulate some recommendations for future research. More research is necessary to disentangle which mechanisms explain the associations of the forms of capital with health. The different types of interplay between the forms of capital deserve more attention in future studies. Future research should examine the relational aspect of social position, possibly by means of multiple correspondence analysis. The complexity of conceptualising social capital as a network-based resource should be examined: especially the relation between the resources of one's network members and other network-based concepts might be interesting. Finally, the cultural capital component of Bourdieu's capital theory deserves extra attention. This relates to measurements of attitudes, preferences, tastes, health-related cultural capital and the association between these cultural capital indicators.

Despite the shortcomings, our study indicates the necessity of including three forms of capital simultaneously and, moreover, demonstrates the importance of cultural capital in understanding differences in physical health perceptions.

Address for correspondence: John Lievens, Department of Sociology, Ghent University Korte Meer 5, 9000 Ghent (Belgium). e-mail: john.lievens@ugent.be

\section{Acknowledgements}

The Sexpert study group consists of Ann Buysse (Ghent University: Department of Experimental Clinical and Health Psychology), Paul Enzlin (Catholic University Leuven, Department of Development and Regeneration, Institute for Family and Sexuality Studies and University Psychiatric Center Catholic Leuven, Context - centre for couple, family and sex therapy), Guy T'Sjoen (Ghent University Hospital: Department of Endocrinology and Centre for Sexology and Gender Problems), John Lievens, Mieke Van Houtte and Hans Vermeersch (Ghent University: Department of Sociology, Research Team Cultural Diversity: Opportunities and Socialisation). The Sexpert study was funded by the Strategic Basic Research program of the Flemish Agency for Innovation by Science and Technology.

\section{References}

Abel, T. (2007) Cultural capital in health promotion. In McQueen, D., Kickbusch, I., Potvin, L., Pelikan, J.M., et al. (eds) Health and Modernity. New York: Springer.

Abel, T. (2008) Cultural capital and social inequality in health, Journal of Epidemiological Community Health, 62, 7. doi:10.1136/jech.2007.066159.

Abel, T. and Frohlich, K.L. (2012) Capitals and capabilities: linking structure and agency to reduce health inequalities, Social Science \& Medicine, 74, 2, 236-44.

Adler, N.E., Boyce, T., Chesney, M.A., Cohen, S., et al. (1994) Socioeconomic status and health: the challenge of the gradient, American Psychologist, 49, 1, 15-24.

Bennett, T., Savage, M., Silva, E., Warde, A., et al. (2009) Culture, Class, Distinction. London: Routledge.

Bourdieu, P. (1984) Distinction. a Social Critique of the Judgement of Taste. London: Routledge.

Bourdieu, P. (1986) The forms of capital. In Richardson, J. (ed.) Handbook of Theory and Research for the Sociology of Education. New York: Greenwood.

Bourdieu, P. (2000) Pascalian Meditations. Cambridge: Polity Press.

Buysse, A., Caen, M., Dewaele, A., Enzlin, P., et al. (2013) Sexpert: Seksuele gezondheid in Vlaanderen (Sexpert: sexual health in Flanders). Ghent: Academia Press. 
Bygren, L.O., Weissglas, G., Wikström, B.-M., Konlaan, B.B., et al. (2009a) Cultural participation and health: a randomized controlled trial among medical care staff, Psychosomatic Medicine, 71, 4, 469-73.

Bygren, L.O., Johansson, S.E., Konlaan, B.B., Grijbovski, A.M., et al. (2009b) Attending cultural events and cancer mortality: a Swedish cohort study, Arts \& Health, 1, 1, 64-73.

Carpiano, R.M. (2006) Toward a neighborhood resource-based theory of social capital for health: Can Bourdieu and sociology help?, Social Science \& Medicine, 62, 1, 165-75.

Carpiano, R.M., Link, B.G. and Phelan, J.C. (2008) Social inequality in health: future directions for the fundamental cause explanation. In Lareau, A. and Dalton, C. (eds) Social Class: How Does It Work?. New York: Russell Sage.

Cockerham, W.C. (2005) Health lifestyle theory and the convergence of agency and structure, Journal of Health and Social Behavior, 46, 1, 51-67.

Cuypers, K., Krokstad, S., Holmen, T.L., Knudtsen, M.S., et al. (2012) Patterns of receptive and creative cultural activities and their association with perceived health, anxiety, depression and satisfaction with life among adults: the HUNT study, Norway, Journal of Epidemiology and Community Health, 66, 8, 698-703.

Daenekindt, S. and Roose, H. (2012) A mise-en-scène of the shattered habitus: the effect of social mobility on aesthetic dispositions towards films, European Sociological Review, 29, 1, 48-59.

Elchardus, M. (2009) Self-control as social control: the emergence of symbolic society, Poetics, 37, 2, 146-61.

Frie, K.G. and Janssen, C. (2009) Social inequality, lifestyles and health. A non-linear canonical correlation analysis based on the approach of Pierre Bourdieu, International Journal of Public Health, 54, 4, 213-21.

Gandek, B., Ware, J.E., Aaronson, N.K., Apolone, G., et al. (1998) Cross-validation of item selection and scoring for the SF-12 health survey in nine countries: results from the IQOLA project, Journal of Clinical Epidemiology, 51, 11, 1171-8.

Glass, T.A., Mendes de Leon, C., Marottoli, R.A. and Berkman, L.F. (1999) Population based study of social and productive activities as predictors of survival among elderly Americans, BMJ, 31, 7228, 478-83.

Grineski, S.E. (2009) Parental accounts of children's asthma care: the role of cultural and social capital in health disparities, Sociological Focus, 42, 2, 107-32.

Grossi, E., Blessi, G.T., Sacco, P.L. and Buscema, M. (2011) The interaction between culture, health and psychological well-being: data mining from the Italian culture and well-being project, Journal of Happiness Studies, 13, 1, 129-48.

Hyyppä, M.T., Mäki, J., Impivaara, O. and Aromaa, A. (2005) Leisure participation predicts survival: a population-based study in Finland, Health Promotion International, 21, 1, 5-12.

Johansson, S.E., Konlaan, B.B. and Bygren, L.O. (2001) Sustaining habits of attending cultural events and maintenance of health: a longitudinal study, Health Promotion International, 16, 3, 229-34.

Kamin, T., Kolar, A. and Steiner, P.M. (2013) The role of cultural capital in producing good health: a propensity score study, Slovenian Journal of Public Health, 52, 2, 108-18.

Katz-Gerro, T. (2004) Cultural consumption research: review of methodology, theory, and consequence, International Review of Sociology, 14, 1, 11-29.

Khawaja, M. and Mowafi, M. (2006) Cultural capital and self-rated health in low income women: evidence from the urban health study, Beirut, Lebanon, Journal of Urban Health, 83, 3, 444-58.

Konlaan, B.B., Bygren, L.O. and Johansson, S.-E. (2000) Visiting the cinema, concerts, museums or art exhibitions as determinant of survival: a Swedish fourteen-year cohort follow-up, Scandinavian Journal of Public Health, 28, 3, 174-78.

Krieger, N., Williams, D.R. and Moss, N.E. (1997) Measuring social class in US public health research: concepts, methodologies, and guidelines, Annual Review of Public Health, 18, 341-378.

Liberatos, P., Link, B.G. and Kelsey, J.L. (1998) The measurement of social class in epidemiology, Epidemiological Review, 10, 1, 87-121.

Mackenbach, J.P. (2012) The persistence of health inequalities in modern welfare states: the explanation of a paradox, Social Science \& Medicine, 75, 4, 761-9.

Mirowsky, J. and Ross, C. (2003) Education, social status and health. New York: Aldine De Gruyter. 
Morrow, V. (1999) Conceptualising social capital in relation to the well-being of children and young people: a critical review, Sociological Review, 47, 744-65.

Muntaner, C., Borrel, C., Benach, C., Pasarin, M.I., et al. (2003) The association of social class and social stratification with patterns of general and mental health in a Spanish population, International Journal of Epidemiology, 32, 6, 950-8.

Nummela, O., Sulander, T., Rahkonen, O. and Uutela, A. (2008) Associations of self-rated health with different forms of leisure activities among ageing people, International Journal of Public Health, 53, 5, 227-235.

Pampel, F.C. (2012) Does reading keep you thin?, Leisure activities, cultural tastes, and body weight in comparative perspective, Sociology of Health \& Illness, 34, 3, 396-411.

Prandy, K. (1999) Class, stratification and inequalities in health: a comparison of the Registrar-General's social classes and the Cambridge scale, Sociology of Health \& Illness, 21, 4, 466-84.

Sampson, R.J., Raudenbush, S.W. and Earl, F. (1997) Neighborhoods and violent crime: a multilevel study of collective efficacy, Science, 277, 5328, 918-24.

Shim, J.K. (2010) Cultural health capital: a theoretical approach to understanding health care interactions and the dynamics of unequal treatment, Journal of Health and Social Behavior, 51, 1-15.

Song, L. (2011) Social capital and psychological distress, Journal of Health and Social Behavior, 52, 478-92.

Song, L. (2013) Social capital and health. In Cockerham, W.C. (ed.) Medical Sociology on the Move. London: Springer.

Stephens, C. (2008) Social capital in its place: using social theory to understand social capital and inequalities in health, Social Science \& Medicine, 66, 6, 1174-84.

Väänänen, A., Murray, M., Koskinen, A., Vahtera, J., et al. (2009) Engagement in cultural activities and cause-specific mortality: prospective cohort study, Preventive Medicine, 49I, 2-3, 142-7.

Veenstra, G. (2007) Social space, social class and Bourdieu: health inequalities in British Columbia, Canada, Health and Place, 13, 1, 14-31.

Veenstra, G. and Patterson, A.C. (2012) Capital relations and health: mediating and moderating effects of cultural, economic and social capitals on mortality in Alameda County, California, International Journal of Health Services, 42, 2, 277-91.

Ware, J. Jr, Kosinski, M. and Keller, S.D. (1996) A 12-item short-form health survey, Construction of scales and preliminary tests of reliability and validity, Medical Care, 34, 3, 220-33.

Wilkinson, A.V., Waters, A.J., Bygren, L.O. and Tarlov, A.R. (2007) Are variations in rates of attending cultural activities associated with population health in the United States?, BMC Public Health, 7, 1, 226-31.

Yaish, M. and Katz-Gerro, T. (2010) Disentangling 'cultural capital': the consequences of cultural and economic resources for taste and participation, European Sociological Review, 28, 2, 169-85.

Ziersch, A.M. (2005) Health implications of access to social capital: findings from an Australian study, Social Science \& Medicine, 61, 10, 2119-31. 